\title{
Categorizing and measurement satellite image processing of fire in the forest greece using remote sensing
}

\author{
Ali Abdulwahhab Mohammed ${ }^{1}$, Hussein Thary Khamees ${ }^{2}$ \\ ${ }^{1}$ Department of Remote Sensing, College of Remote Sensing and Geophysics, Al-Karkh University of Science, Baghdad, \\ Iraq \\ ${ }^{2}$ Department of Laser and Optoelectronic Engineering, College of Engineering, Al-Nahrain University, Baghdad, Iraq,
}

\begin{tabular}{l}
\hline \hline Article Info \\
\hline Article history: \\
Received Aug 21, 2020 \\
Revised Oct 9, 2020 \\
Accepted Oct 23, 2020 \\
\hline
\end{tabular}

\section{Keywords:}

Categorizing image

Fires

Moment feature

Remote sensing

Sentinel-2A

\begin{abstract}
in this paper, a polar-orbiting satellite has been used called Sentinel-2A imagery, multispectral high-resolution to cover Athens city, Greece that located at latitude $\left(37^{\circ} 58^{\prime} 46^{\prime \prime}\right) \mathrm{N},\left(23^{\circ} 42^{\prime} 58^{\prime \prime}\right)$ E., the work aims to measurement and study the wildfires natural resourcesbefore and after fire break out that happenedin forests of Athens city in Greece for a year (2007, 2018) and analysis the damage caused by these wildfiresand their impact on environment and soil by Categorize the satellite images for the interested region before and after wildfires for a years (2007, 2018 respectively) and the region covered of every class has been calculated and discuss their techniques and lessen or limit the rapidly spreading wildfires damage. The categorizing utilizing the moments with (K-Means) grouping algorithm in RS (remote sensing). And the categorizing results show five unique classes (water, trees, buildings without tree, buildings with tree, bare lands) where, it can be observed that the area covered by every class before and after wildfires and the changed pixels for all classes. The trial results of categorizing mechanism presents that the perfect performance accuracy with a pretty categorizing and result analysisa bout the harms resulted from the fires in the forest Greece for a years (2007 and 2018).
\end{abstract}

This is an open access article under the CC BY-SA license.

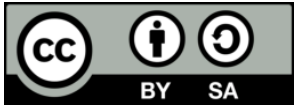

\section{Corresponding Author:}

Ali Abdulwahhab Mohammed

Department of Remote Sensing, College of Remote Sensing and Geophysics

Al-Karkh University of Science

Al-Karkh Side, Haifa St. Hamada, Baghdad, Iraq

Email: ali_abdulwahhab@kus.edu.iq

\section{INTRODUCTION}

Remote sensing technology has been utilized during the last few decades to study land cover and earth observation to survey the distribution quantity of natural planet resources. Remote Sensing has been developed in spectral, spatial and temporal resolution to utilize satellite images for choosing area, mapping, understanding, evaluation, accuracy computation of image and error modulation $[1,2]$. Image categorizing is one of a decent strategy in digital image preparing for land-cover information abstraction and utilizing the data holds in remotely sensed pictures. Wherever, the classes are recognized to a characterized topical class (water, trees, building without trees, buildings with trees, and bare lands) [3-5]. Satellite image categorizing is broadly utilized for extracting the spectral highlights from satellite images and analyze land-cover map of the area selected [6-8]. Where, the categorizing techniques can be defined as two significant types: unsupervised and supervised categorizing [9, 10]. The study picked for research is front of the zone of Athens town in Greece taken by (Sentinel-2(Optical)) by a resolution 10 meters Shown in the Figure 1. 

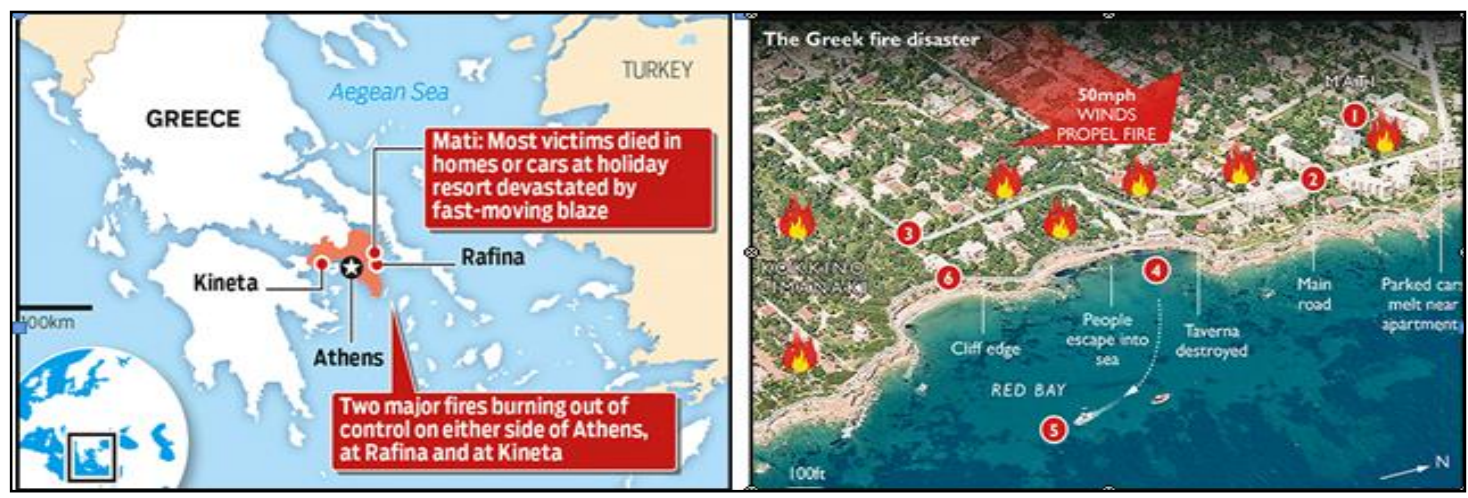

Figure 1. Positionof study area in Athens city (Greece)

Actually, there are several jobs that have related with satellite images and teach the perspicacity and gather the benefit of the achievement the huge data [11-13]. This data is utilized to predict coming environmental disasters or modifies in climatic situationand numerous different possessions in numerous everyday matters. Now are a portion of the the whole thing that have been researched andconsidered in this scope. In [14-16], describe the scope harms and dangers in turkey especially through Aegean and Mediterranean areas caused by the fires of Forest. Numerous digital image processing methods utlized to study the wildfire categorizing and compute the wildfire influenced on the burned areas. In [17, 18], shown the object of categorization that are based on develop categorization proceedings for the map of burning area and a series damages of fires that happened throughout of the summers (2007 and 2009) in Country Greece, by providing pour a system " l'Observation de la Terre (SPOT)4 HRVIR images". In [19-21], state a categorize of satellite image environment utilizing a creative technique called reflection based on phenology method (RBPM). Anywhere, the datasets of the landsat8has was utilized thatsave imagery in multispectral. The source of the reflection of band values is utilized in the categorizing process. The categorizing accuracy of the PRBM method utilized overall accuracy, confused matrix, and kappa coefficient as a quality measurement. In [22, 23], State a categorizing technique used to discover the classes of land cover in satellite images. In this work, the categorizing techniques that utilized are supervised categorizing, unsupervised categorizing and Object-orientedcategorizing. The moment feature clustering technique is utilized in this paper as unsupervised categorizing for the Athens city region in Greece to categorize the fires, serious damages and threats that happen in that area. The rest sections of paper are as follows: in Section 2 illustrates the problem statement. Section 3 illustrates and weproposed system diagram about image categorizing techniques. A Section 4 describes the experimental results and analysis of results. Finally, we have given in Section 5 the conclusions with future suggestions.

\section{PROBLEM STATEMENT}

The greatest significant factors of applying the regionof Athens downtown in Greece are the wildfires causing immense harms in this area and having (five types of land cover classes) and being applied as funding for recognize. These kinds of classes are agricultural area Buildings Without trees, rivers, Agricultural region. Buildings with trees, and bare lands, where, the areas in which fires happen are determined by utilizing techniques to categorize it and discuss the impact of fires on each area covered by each class. Satellite image of that area was taken by (Sentinel-2 Optical) with resolution 10 meters. The categorized images before and after the fire are analyst and studied to calculate the amount of damaged buildings happening and fires, in the forests of Greece between years (2007 and 2018).

\section{PROPOSED SYSTEM DIAGRAM}

The features of the similar districts in picturecanbe categorized by using the elements of apparentunderstanding. The categorizing technique can be unsupervised or supervised classifications to be away into a clear class based on the number of ectractedfeaturesand acknowledged with that image apparent [22]. The satellite image contains many properties for example; casing of remote sens for spectral area, and every one of highlights properties exists in separate class [24]. In supervising categorization; the classes are demonstrated by giving a group sample of analysed information to the administer [17]. The based moments of K-means algorithm is employed to extricate wholly features and categorize image and the Figure 2 shows impressions of the proposed the method for categorizing. 


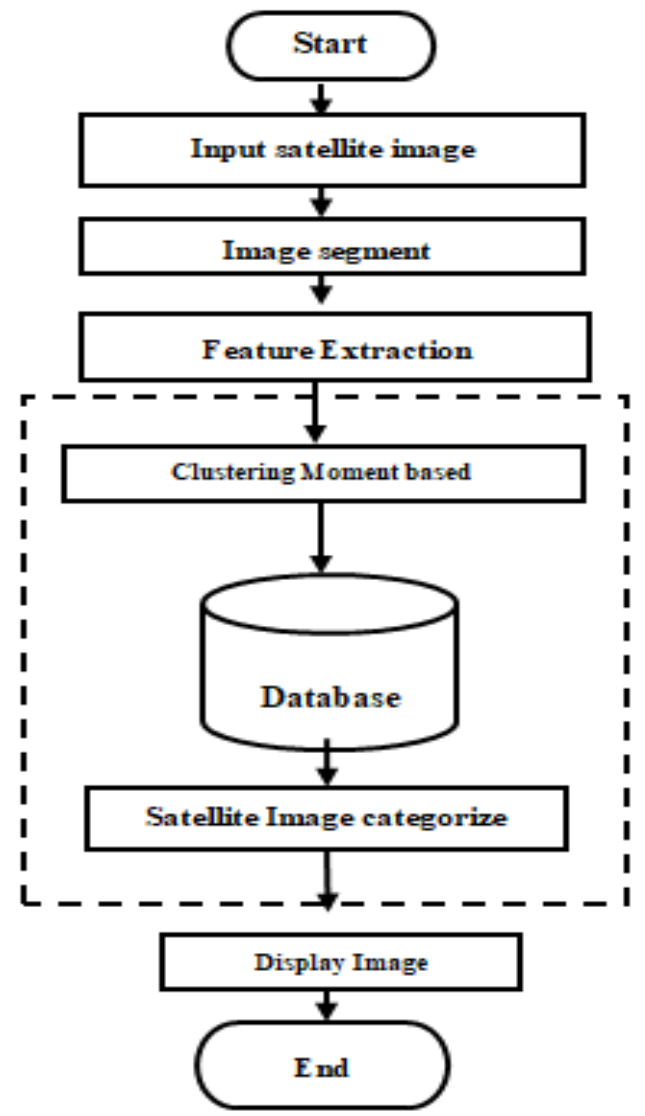

Figure 2. Block diagram of techniquesatellite categorizing

\subsection{Input satellite images}

The input image is satellite imagery taken by (Sentinel-2A) satellite covered Athens downtown, Greece that situated at scope $37^{\circ} 58^{\prime} 46^{\prime \prime} \mathrm{N}, 23^{\circ} 42^{\prime} 58^{\prime \prime} \mathrm{E}$ with the multispectral high-resolution. The Greece image was caught by (Sentinel-2 Optical) with resolution 10 meters. It covers the wildfires (natural resources) before and after fire break out that happened in forests for between years $(2007,2018)$. Table 1 presents the informationtechnical of original image and the original satellite image of Greece before and after the fire between years $(2007,2018)$ arepresented In the Figures 3 and 4 respectively.

Table 1. Data about of Input image

\begin{tabular}{|c|c|c|c|c|}
\hline "Product" & "Satellite/Sensor" & "Resolution" & "Acquired Date" & "Band Combination" \\
\hline $\begin{array}{l}\text { Geo Tiff } \\
\text { format }\end{array}$ & $\begin{array}{l}\text { Sentinel-2 } \\
\text { (Optical) }\end{array}$ & 10 meters & $\begin{array}{l}20 \text { July } 2018 \& 30 \text { July } \\
2018\end{array}$ & $\begin{array}{c}4,3,2 \text { (R-G-B) Visible color \& 8,4,2 (R-G-B) False } \\
\text { color layers }\end{array}$ \\
\hline
\end{tabular}

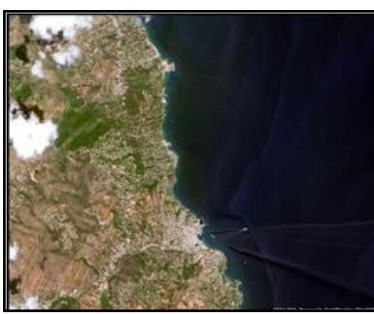

(a) Mati-Greecebefore Fires

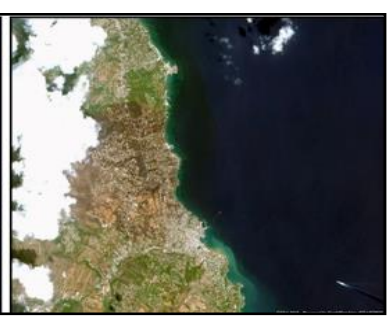

(b) Mati-Greeceafter Fires

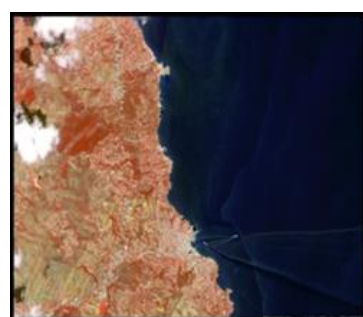

(a) Mati-Greecebefore Fires

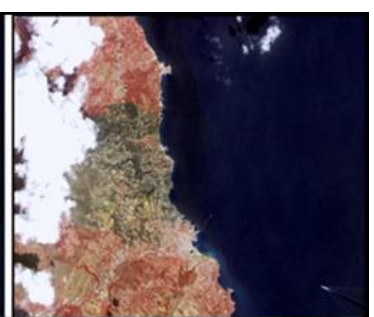

(b) Mati-Greeceafter Fires

Figure 3. The images represent Mati-Greece before and after Wildfires for a year 2007

Figure 4. The images represent Mati-Greece before and after Wildfires for a year 2018 


\subsection{Image enhancement and segmentation}

In this paper is shown upgrade for appearative visual to the image by utilizing preprocessing. This stage isrelied upon focus on every pixelwithout effecting of the correlation contiguous pixels and forimproves the recognizing between the image highlights applies the following connection on the image [19]:

$A_{e}(q, z)=\operatorname{round}\left[\left(A_{o}(q, z)-H\right) /(H-L) * 255\right]$

Where, $A_{e}(q, z)$ refers to the new image upgraded, $A_{o}(q, z)$ represents to the (input image), and $\mathrm{q}, \mathrm{z}$ isalludingto the files of the pixel in the image. Halludesto theupper (1\%) for pixels estimations of (input image) andLalludes to the bottom (1\%) of pixels estimations of (input image) [25-27].

The division of the image can be defined as a process to dividing it into of the block squares of regularsize. And we find process isn't concerned during the spectral scattering of image, it are simply partition geometrical. In this work, the size of everyblock square is $(4 \times 4)$, where, it relies at the measure of the image spatial resolution. Where; the lower image resolution are isolated to squared number less than higher image resolution. In order to adoptesuitabledata is checked in everythesquare block.

\subsection{Feature extract}

The moments can be utilized to differentiate images as estimation that dependent on their highlights of color [23]. The features of moment can be described as a particular of numericalquantity that utlized to extract data set in theblock of image. Where, the mass alludes to a set distribution of (pixels), the (firstordered moment) to given in (2) is utilized to extract the moment features.

$$
\mathrm{M}=\mathrm{r} \times F_{P} \quad(2)
$$

Where in (2), the (applied force $\left(F_{P}\right)$ ), can be represent as the ( pixel of block)and the distance can be refer to $\mathrm{r}$ from the center of block to the (applied force $\left(F_{P}\right)$ ).

1) determined the (distance $\left(d_{s}\right)$ ) that mean (between each the (pixel in specific square)and of the center of square) anddepends on the position of pixel by utilized of the following procedure:

a) The 1 's quarter the distance $\left(d_{s 1}\right)$ is calculated by utilized the equation:

$$
d_{s 1}=\sqrt{\left(\left|x-x_{o}\right|-1 / 2\right)^{2}+\left(\left|y-y_{o}\right|-1 / 2\right)^{2}}
$$

b) The 2 ' s quarter the distance $\left(d_{s 2}\right)$ is computedutilizedthe following equation:

$$
d_{s 2}=\sqrt{\left(\left|x-x_{o}\right|-1 / 2\right)^{2}+\left(\left|y-y_{o}\right|+1 / 2\right)^{2}}
$$

c) The 3 ' s quarter the distance $\left(d_{s 3}\right)$ is computed by utilized the equation:

$$
d_{s 3}=\sqrt{\left(\left|x-x_{o}\right|+1 / 2\right)^{2}+\left(\left|y-y_{o}\right|+1 / 2\right)^{2}}
$$

d) Finally, this equation is the4 's quarter the distance $\left(d_{s 4}\right)$, can be computed by the following equation:

$$
d_{s 4}=\sqrt{\left(\left|x-x_{o}\right|+1 / 2\right)^{2}+\left(\left|y-y_{o}\right|+1 / 2\right)^{2}}
$$

Where, $\mathrm{x}, \mathrm{y}$ are indices of pixel in a squareand $x_{0}, y_{0}$ refers to the indices of the center square.

2) We can calculate the momentfeature of pixel $F M_{p}(I,, j)$ in a definitesquarein the image by applying the following ofrelation:

$$
F M_{p}(i, j)=F_{P}(i, j) \mathrm{x} d_{s}
$$

3) The ((moment features of a specific square $)(M B))$ in the image, and can be determined by utilized of the following ofrelation:

$$
M B(x, y)=\frac{1}{B_{h} \times B_{w}} \sum_{x=0}^{B_{h}} \sum_{y=0}^{B_{w}} M_{p}(x, y)
$$


Where, $B_{w}$ refers to the width of square, and $B_{h}$ referstothe height of square, and $F_{P}(i, j)$ refers the value pixel of selected square. $(I, \mathrm{j})$ is the (pixel indices) in selected squareofof image.

\subsection{Clustering satellite image}

In this step, the implementation of K-Means procedure is utilized by two input parameters, the first is moment feature values of whollyquadrangles of image and the second is the number of clusters. The moment feature is extracted for each image square and put away in the two dimentional array, and the KMeans procedure is useful and gathering of all these highlights to get the best of the features (centroids). Where, pixels esteem in the image belongs to each centroid are put away as a vector in database that utilized in the image categorizing.

\subsection{Satellite image categorizing and analsisy}

The Greece categorizing step is done after the gathering of highpoints and kept in database. The categorizing methodtrusts upon the checkupforspectring amount to allpixels in the (built-up database), based to the nearness for all (pixels) into the classes available in a database. Categorizing method are accomplishedby determining the similarityvaluation $\left(S_{\mathrm{q}}\right)$ between eachtheimage (pixel) $\mathrm{F}_{\mathrm{xy}}$, the average $\mu$ by put on the (9), the maximumvalueSqrfers to pixel in image valuation for every class [25].

$$
\mathrm{S}_{\mathrm{q}}=\left(1-\left|\mu-\mathrm{F}_{\mathrm{xy}}\right|\right)
$$

\section{EXPERIMENTAL RESULTSAND ANALSISY}

The greatest significant factors of utilized the Athens city area in Greece images having the five types of the classes and being applied as assistance for clarification. It completed to discourse the variances between a classes and learning the area of safe by every (class). An images occupied by the (Sentinel-2A) satellite covered in Athens city, Greece that situated at scope $\left(37^{\circ} 58^{\prime} 46^{\prime \prime}\right) \mathrm{N},\left(23^{\circ} 42^{\prime} 58^{\prime \prime}\right) \mathrm{E}$. In this work, the input images categorized before and after the Wildfires for a years (2007 and 2018). Where, the variations of the spectral highlights in these images give five classes: (water, trees area, buildings without trees, buildings with trees, and bare lands). After stratifythecategorizemethod, the database contains feature of moment element valuationsforsquares of imageidenticalfor the latterbestcentroidsachievedfrom applying the k-means on the squares of image, where the numberofrepetitionprobabletogrowgathering and best centroids before and after (Wildfires) the image of Greece shown in Figure $3(\mathrm{a}, \mathrm{b})$ are 6, 2 respectively a year (2007). The Five classes with best Centroids characterise feature for definite squares of categorized image. The Figures 5 and 6 show a classes with the best Centroids the categorized image before and after the (Wildfires For) a year (2007). Although, the region covered by individually class in categorized images can be calculatefor a year (2007 and 2018) by applying the (10).

Area Coverd $\left(\mathrm{m}^{2}\right)=($ No. of Pixels $) \times 10^{2}$

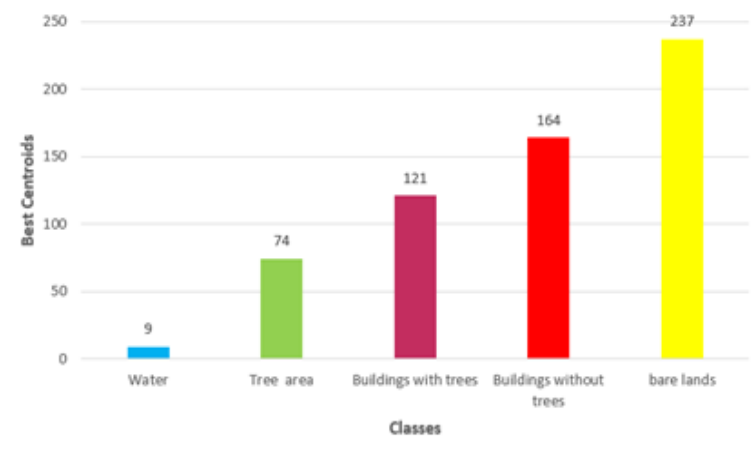

Figure 5. Five classes with the best centroids before fires in 2007

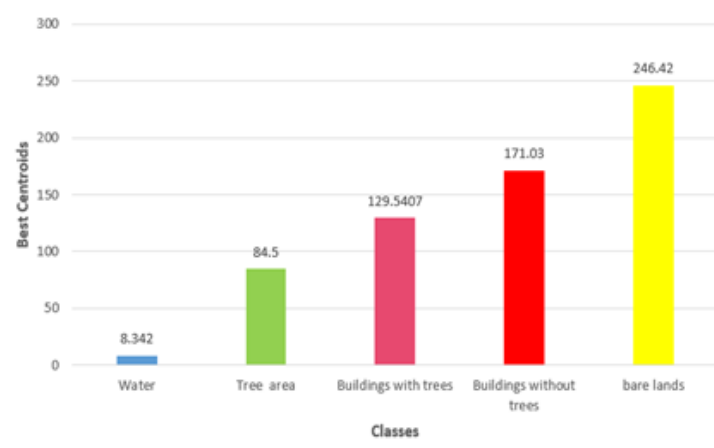

Figure 6. Five classes with the best centroids after fires in 2007

The categorizing results of images of Greecebefore and after (Wildfires) for years (2007) are presented in Figure 7. The trial results as presented in Figure 8 illuminated the region covered by every class before and after Wildfires in Greece for a year (2007) was changed and detects the damage caused by these fires and their effect on environment and soil. 
Water
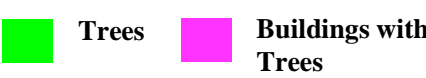

Buildings without

Tress

Bare lands

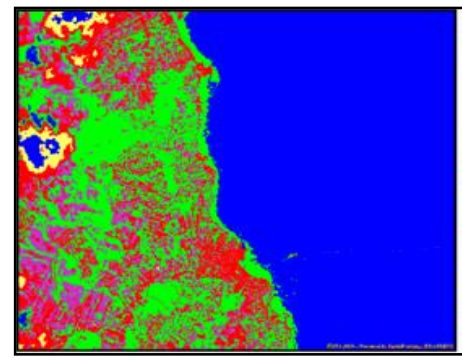

a) Before Wildfires

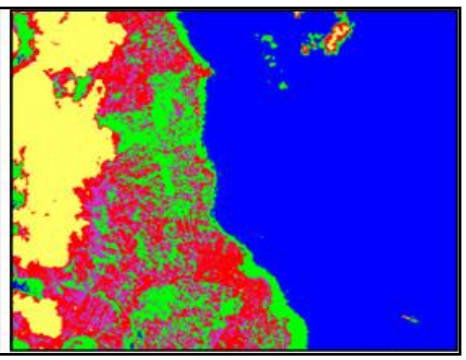

b) After Wildfires

Figure 7. The categorized images of Greece before and after Wildfires for a year (2007)

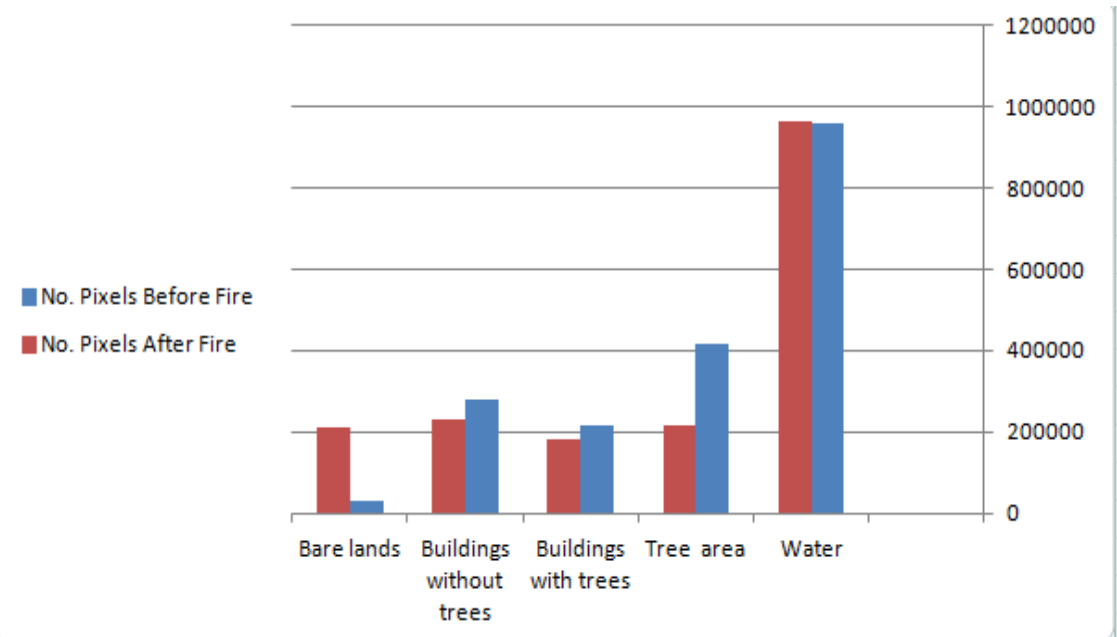

Figure 8. The effect on No. pixel for every class in categorized image before and after fire in (2007)

In the other side, the number of cycles needed to get convergence and best centroids before and after (Wildfiresin) the image of Greece as shown in Figure 4 (a, b) are 5, 6 respectively for a year (2018). Figures 9 and 10 describe the best centroids for the categorized image before and after the (Wildfires) for a year (2018). The results of test appeared in Table 2 and 3 illuminatedtheregion secured by every class before and after (Wildfiresin) in Greece for a year (2018) was changed and identify the damage caused by these fires and their effect on environmentsoil and soil. The categorizing results of images of Greecebefore and after (Wildfires) for a year (2018) is shown in Figure 11, its notice there are five unique classes.

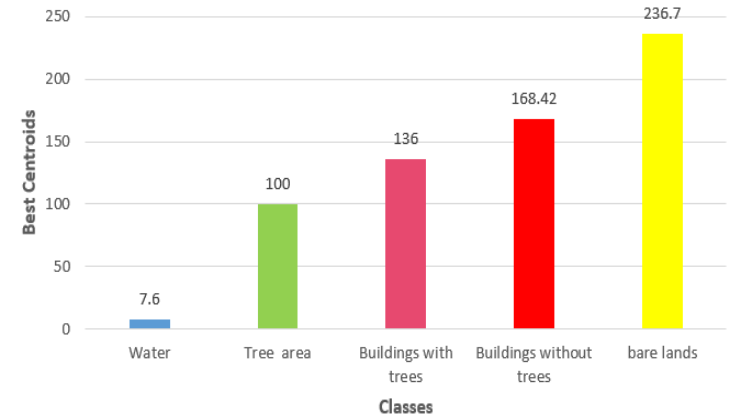

Figure 9. Best centroids for five classes after fires in (2018).

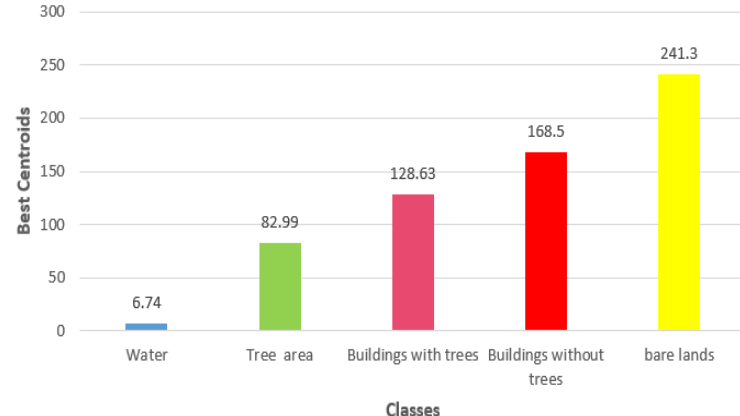

Figure 10. Best centroids for five classes before fires in (2018) 
Table 2. The cover regionand No. of pixel for every class in categorized image before fire in (2018)

\begin{tabular}{lcc}
\hline \multicolumn{1}{c}{ Classes } & $\begin{array}{c}\text { No. } \\
\text { Pixels }\end{array}$ & $\begin{array}{c}\text { Area Covers }\left(\mathrm{m}^{2}\right) \\
(\text { No. Pixels *10) }\end{array}$ \\
\hline Water & 976500 & 9765000 \\
Tree area & 164780 & 1647800 \\
Buildings with trees & 258928 & 2589280 \\
Buildings without trees & 427780 & 4277800 \\
Bare lands & 21612 & 216120 \\
\hline
\end{tabular}

Table 3. The cover regionand No. of pixel for every class in categorized image after fire in (2018)

\begin{tabular}{lcc}
\hline \multicolumn{1}{c}{ Classes } & $\begin{array}{c}\text { No. } \\
\text { Pixels }\end{array}$ & $\begin{array}{c}\text { Area Covers }\left(\mathrm{m}^{2}\right) \\
(\text { No. Pixels *10) }\end{array}$ \\
\hline Water & 961896 & 9618960 \\
Tree area & 132647 & 1326470 \\
Buildings with trees & 184336 & 1843360 \\
Buildings without trees & 278648 & 2786480 \\
Bare lands & 242516 & 2425160 \\
\hline
\end{tabular}

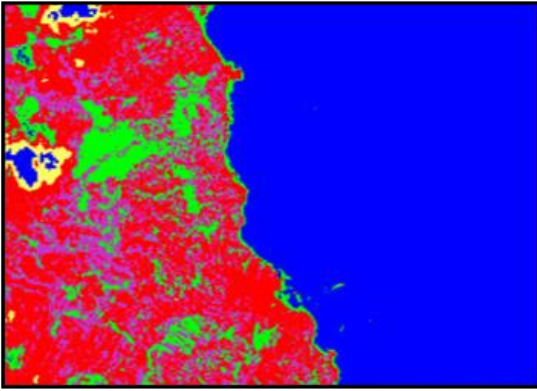

a) Before Wildfires

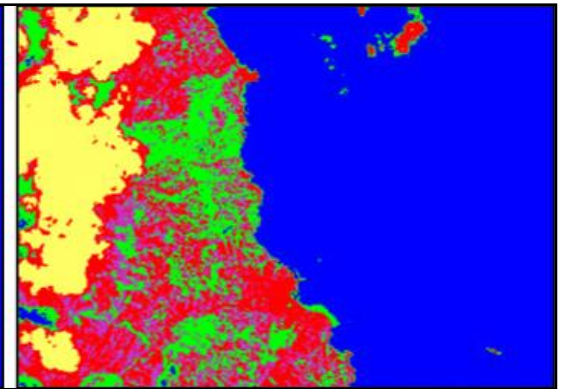

b) After Wildfires

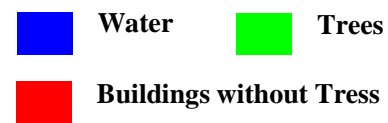

Buildings with Trees

Bare lands

Figure 11. The categorized images of Greece before and after Wildfires for a year (2018)

The experimental from resulted about of the proposed categorizing approachpresents that good of the performance accurateness of the image categorized taken by Sentinel-2A satellite and give the great analysis results about a damages about because the fires in the forest Greece for a years (2007 and 2018). In a year (2007 A.D.) the tree class is covered the zone (4168920 $\mathrm{m} 2$ before Wildfires), while (after the Wildfires it's covered the zone $2137120 \mathrm{~m} 2)$. Otherwise, the building with trees class is covered the zone $(2138040 \mathrm{~m} 2$ before Wildfires), while (after Wildfires it's covered $1825720 \mathrm{~m} 2$ ). Also, the (bare lands class is covered the zone $291440 \mathrm{~m} 2$ before Wildfires), but (after the Wildfires it's covered $2124000 \mathrm{~m} 2$ ). And the natural images of Greece after Wildfires that alludes to the gigantic harmed in the Athena city. After the Wildfires that occurred in the Greece in (2007) and during the eleven years back turned into the zone covered by the class of trees in (2018) is $(1647800 \mathrm{~m} 2)$, the region covered by the class of bare lands is $(216120 \mathrm{~m} 2)$, and the zone covered by the class of building with trees is $(2859280 \mathrm{~m} 2)$. The observed from the result analysis about the harms resulted because of the fires in the forest Greece for a years (2007 and 2018) where, the number of pixel for class (tree and trees with building) are increasing after (wildfires) in (2007) that refers the size of the development in culturing and reconstruction of buildings during 11 years ago to (2018) which implies that the exactness of proposed categorizing technique for this study.

\section{CONCLUSION AND FUTURE WORK}

Satellite (Sentinel-2A)imageryis a polar-orbiting, multispectral high-resolution satellite that cover Athensdowntown, Greece that located at latitude $\left(37^{\circ} 58^{\prime} 46^{\prime \prime}\right) \mathrm{N},\left(23^{\circ} 42^{\prime} 58^{\prime \prime}\right)$ E. In this work, noticed the influenced zone, the burned zones. It observed the impact on each class before and after the fires that happened in forests of Athens city in Greece for a years (2007 and 2018). The experimental of resulted presents that good of the performance correctness in categorizing with five various classes (trees, water, bare lands, buildings with tree, buildings without tree ) and good result and analysis about damages resulted from the fires in the forest Greece for a years (2007 and 2018) where, the number of pixel for class (building with tree and trees) are increasing after (wildfires) in (2007) that refers the size of the development in culturing and reconstruction of buildings during 11 years ago to (2018) which means that the accuracy of proposed categorizing technique is best for this study. For future paper, utilized another landsat satellite image for the same zone with SVM or genetic algorithm categorizing 


\section{REFERENCES}

[1] Patino, Jorge E., and Juan C. Duque. "A review of regional science applications of satellite remote sensing in urban settings." Computers, Environment and Urban Systems, vol. 37, pp 1-17, 2013.

[2] K. Radhika, S.Varadarajan "Satellite Image Classification of Different Resolution Images Using Cluster Ensemble Techniques" researchgate, 2017.

[3] Jog, Sayali, and Mrudul Dixit. "Supervised classification of satellite images." In 2016 Conference on Advances in Signal Processing (CASP), pp. 93-98. IEEE, 2016.

[4] Assad H. Thary Al-Ghrairi, Mohammed S. Mahdi Al-Taei "KMeans based SVD for Multiband Satellite Image Classification", International Journal of Scientific \& Engineering Research, vol. 7, no. 8, ISSN 2229-5518, 2016.

[5] R. Mohamed et al.," Bat algorithm and k-means techniques for classification performance improvement." Indonesian Journal of Electrical Engineering and Computer Science, vol. 15, no. 3, pp. 1411-1418, 2019.

[6] Assad H. Thary Al-Ghrairi, Hussein Thary Khamees, Ali A. Mohammed, HarithM.Saeed, Walaa S. Tahlok, andZahraa H. Abed, " Classify and Analysis of Fire in the Forest Greece Using Remote Sensing", International Journal of Scientific \& Engineering Research, vol. 10, no. 10. Pp. 1364-1371, 2019.

[7] Ablin, R., C. Helen Sulochana, and G. Prabin. "An investigation in satellite images based on image enhancement techniques." European Journal of Remote Sensing, pp 1-9, 2019.

[8] S.ManthiraMoorthi, IndranilMisra, "Kernel based learning approach for satellite image classification using support vector machine", Recent Advances in Intelligent Computational Systems (RAICS), IEEE, 2011. 10.1109/RAICS.2011.6069282, ISBN: 978-1-4244-9478-1,

[9] Mohammed S. Mahdi Al-Taei, Assad H. Thary Al-Ghrairi, "Satellite Image Classification Using Moment and SVD Method", International Journal of Computer, vol. 23, no. 1, pp. 10-34, 2016.

[10] Hnatushenko, Vik V., Vik Hnatushenko, D. K. Mozgovyi, and V. V. Vasiliev. "Satellite Technology of the forest fires Effects Monitoring." Scientific Bulletin of National Mining University, 2016.

[11] Vilar, Lara, Andrea Camia, and Jesús San-Miguel-Ayanz. "A comparison of remote sensing products and forest fire statistics for improving fire information in Mediterranean Europe." European Journal of Remote Sensing 48, no. 1, pp. 345-364, 2015.

[12] Assad H. Thary Al-Ghrairi, "Satellite Image Classification Using K-Means and SVD Techniques", LAP LAMBERT Academic Publishing ISBN: 978-620-2-02145-6, 2017.

[13] Ugur Alganci, Elif Sertela, And Cankut Ormeci, "Forest Fire Damage Estimation Using Remote Sensing and GIS", Remote Sensing for Science, Education, Raine Reuter (Editor) and Natural and Cultural Heritage, 2010.

[14] Abdulkadhem, A. A., \& Al-Assadi, T. A.. "An important landmarks construction for a GIS-Map based on indexing of dolly images." Indonesian Journal of Electrical Engineering and Computer Science 15, no. 1, pp. 451-459, 2019.

[15] Anastasia Polychronaki and Ioannis Z. Gitas. "Burned Area Mapping in Greece Using SPOT-4 HRVIR Images and Object-Based Image Analysis", Remote Sens., pp. 424-438, 2012.

[16] Aliyu, HajaraAbdulkarim, MohdAzhar Abdul Razak, and Rubita Sudirman. "Normal and abnormal red blood cell recognition using image processing." Indonesian Journal of Electrical Engineering and Computer Science, vol. 14, no. 1, pp. 100-104, 2019.

[17] Florin-Andrei Georgescu, Corina Vaduva, DanRaducanu, and Mihai Datcu "Feature Extraction for Patch-based Classification of Multispectral Earth Observation Images", Published in IEEE, vol. 13, no. 6, 2016.

[18] Gure, Mulayim, Mehmet EminOzel, H. Hulya Yildirim, and MuzafferOzdemir. "Use of satellite images for forest fires in area determination and monitoring." In 2009 4th International Conference on Recent Advances in Space Technologies, pp. 27-32, IEEE, 2009.

[19] KR.Sivabalan, E.Ramaraj, "Reflection Based Phenology Mehod for Satellite Image Environmental Classification" Third International Conference on Science Technology Engineering \& Management, 2017.

[20] Abburu, Sunitha, and Suresh Babu Golla. "Satellite image classification methods and techniques: A review." International Journal of Computer Applications, vol. 119, no. 8, 2015.

[21] Rahul Neware, Amreen Khan "Survey on Classification techniques used in remote sensing for satellite images" Researchgate, 2018.

[22] Parameswaran, Namboodiri Sandhya, and D. Venkataraman. "A computer vision based image processing system for depression detection among students for counseling." Indonesian Journal of Electrical Engineering and Computer Science, vol. 14, no. 1, pp. 503-512, 2019.

[23] Anand, U.; Santosh, K. S. and Vipin, G.S., " Impact of features on classification accuracy of IRS LISS-III images using artificial neural network", International Journal of Application or Innovation in Engineering and Management, vol. 3, pp. 311-317, 2014.

[24] Assad H. Thary Al-Ghrairi, Zahraa H. Abed, Fatimah H. Fadhil, and Faten K., "Classification of Satellite Images Based on Color Features Using Remote Sensing”, International Journal of Computer, vol. 31, no. 1, pp 42-52, 2018.

[25] Mahdi, M. S. and Abdul Hassan, A. A.," Satellite Images Classification in Rural Areas Based on Fractal Dimension", Journal of Engineering, vol. 22, no. 4, pp. 147-157, 2016.

[26] Hussein Thary Khamees, Munaf Salih Majeed, "A receiver intensity for Super Lorentz Gaussian beam (SLG) propagation via the moderate turbulent atmosphere using a novelty mathematical model", Journal of Optical Communications, vol. 41, no. 1, pp 1-8, 2020.

[27] Hussein Thary Khamees, Ali A. Mohammed, "Bit Error Rate Evaluation in Atmospheric Blustery for Slant Path Spread of Super Lorentz Gaussian Beam", Journal of Southwest Jiaotong University, vol. 55, no 1, pp. 1-8, 2020. https://doi.org/10.35741/issn.0258-2724.55.1.21 